•编者按・

\title{
红外相机技术在我国自然保护地 野生动物清查与评估中的应用
}

\author{
肖治术 $1,2^{*}$
}

1 (中国科学院动物研究所农业虫害鼠害综合治理研究国家重点实验室, 北京 100101) 2 (中国科学院大学生命科学学院, 北京 100049)

\section{Application of camera trapping to species inventory and assessment of wild animals across China's protected areas}

\author{
Zhishu Xiao ${ }^{1,2 *}$ \\ 1 State Key Laboratory of Integrated Management of Pest Insects and Rodents, Institute of Zoology, Chinese Academy of \\ Sciences, Beijing 100101 \\ 2 College of Life Sciences, University of Chinese Academy of Sciences, Beijing 100049
}

生物资源的本底清查和编目评估是我国各类 自然保护区科研监测的重要任务之一。经过60多年 的建设和发展, 我国自然保护区体系已基本形成, 为保护生物多样性等自然资源发挥了极为重要的 作用。十八大以来, 党和政府提出“美丽中国”、“生 态文明”体制建设, 构建以国家公园为主体的自然 保护地体系, 亟需对现有保护区内野生动植物本底 资源进行全面清查和物种编目评估。然而, 我国各 类自然保护地在野生动植物本底清查、常规监测和 编目评估面临以下共性问题:

(1)国家层面对我国各类自然保护地自然资源 本底编目调查和监测缺乏顶层规划。我国自然保护 区或保护地类型多, 不同类型的保护地空间重叠, 功能定位不明确, 管理部门多, 职能交叉重叠, 缺 乏各部门、各类型保护地的协调机制, 是当前我国 自然保护区资源管理和保护面临的突出问题(欧阳 志云和徐卫华, 2014; 彭杨靖等, 2018)。2018年国家 政府机构改革, 组建了自然资源部, 其中国家林业 和草业局(国家公园管理局)负责对我国以国家公园 为主体的自然保护区及其自然资源进行全面监管 和保护, 有望解决过去 “九龙治水”、顶层规划不足 等重大问题。
(2)多数自然保护区在建立后多年未开展野生 动植物资源本底的全面系统编目调查和常规监测, 许多重要物种的生存现状缺乏基础数据, 无法提供 及时有效的保护管理措施以及生态恢复对策。由于 技术、物力和人力等的限制, 以往各类自然保护地 综合科考的调查范围和覆盖面十分有限, 仅集中于 少数物种和类群, 而多数类群的本底资源及其变化 缺乏有效清查编目, 真实性存疑。

(3)传统调查技术和方法在资源本底清查和常 规监测方面存在明显缺陷, 主观性强、重复性差, 难以在区域和全国尺度上形成相对统一的抽样标 准, 且执行要求高、难度大, 获得的数据质量不高, 严重缺乏可比性和连续性。

(4)许多自然保护地面临领导责任意识不强、技 术管理人才严重短缺、专业调查队伍不稳定、技术 培训不足等基本问题, 难以满足自然保护区基本科 研监测能力建设的需要。

近5年, 全国绝大多数国家级自然保护区均布 设了红外相机用于野生动物调查和评估(李晟等, 2014; 肖治术, 2016)。红外相机技术的广泛应用为 “十八大”以来以国家公园为主体的自然保护地体系 建设提供了可靠的技术和关键科学数据。然而, 在 
红外相机监测与研究过程中面临一系列新的问题, 如种群和群落相关评价指标的计算和认识仍有待 完善, 基于红外相机技术的常规监测与动态评估仍 有待全面推广和实施。鉴于目前红外相机技术在我 国自然保护区野生动物本底清查中的普及应用, 《生物多样性》组织了此 “红外相机数据分析专题”, 包括1篇基于红外相机技术的自然保护区清查与评 估的典型案例和 4 篇数据分析论文。

针对我国自然保护区红外相机清查与编目评 估问题，肖治术等(2019)以广东车八岭国家级自然 保护区全境清查为例, 提出基于红外相机技术逐步 建立我国自然保护区野生动物本底清查和评估的 解决方案, 为我国以国家公园为主体的自然保护地 体系开展自然资源监测与评估的标准化体系建设 提供参考, 并推动我国自然保护区开展基于红外相 机技术的陆生脊椎动物规范化监测与动态评估。针 对我国目前红外相机数据分析中存在的主要问题, 陈立军等(2019b)综述了国内外物种相对多度指数 (relative abundance index, RAI)的应用情况，阐述了 RAI相关计算方法的优势与局限, 分析了RAI相关 指数在我国野生动物编目与评估中的应用情况。肖 文宏等(2019b)通过综述占域模型在动物种群及分 布研究中的应用, 对该模型的原理进行简要阐述, 并提供了案例分析; 肖文宏等(2019a)进一步针对基 于可识别个体的物种如何通过空间标记重捕模型 来估计种群密度进行阐述。陈立军等(2019a)在野生 动物活动节律及其影响因素的基础上，阐述了动物 日活动节律的核密度估计方法。这些文章中，以广 东车八岭保护区和四川青城山森林公园的相关数 据为案例, 为占域模型、空间标记重捕模型和活动 节律等野生动物种群参数和行为指标提供了详细 分析和R代码，便于国内同行参考应用。

\section{参考文献}

Chen LJ, Shu ZF, Xiao ZS (2019a) Application of camera-trapping data to study daily activity patterns of Galliformes in Guangdong Chebaling National Nature Reserve. Biodiversity Science, 27, 266-272. (in Chinese with English abstract) [陈立军, 束祖飞, 肖治术 (2019a) 应用红外相机数据研究动物活动节律一一以广东车八岭 保护区鸡形目鸟类为例. 生物多样性, 27, 266-272.]

Chen LJ, Xiao WH, Xiao ZS (2019b) Limitations of relative abundance indices calculated from camera-trapping data. Biodiversity Science, 27, 243-248. (in Chinese with English abstract) [陈立军, 肖文宏, 肖治术 (2019b) 物种相对多 度指数在红外相机数据分析中的应用及局限. 生物多样 性, 27, 243-248.]

Li S, Wang DJ, Xiao ZS, Li XH, Wang TM, Feng LM, Wang $Y$ (2014) Camera-trapping in wildlife research and conservation in China: Review and outlook. Biodiversity Science, 22, 685-695. (in Chinese with English abstract) [李 晟, 王大军, 肖治术, 李欣海, 王天明, 冯利民, 王云 (2014) 红外相机技术在我国野生动物研究与保护中的应 用与前景. 生物多样性, 22, 685-695.]

Ouyang ZY, Xu WH (2014) Integrating nature protection system and establishing national parks under legislation. Biodiversity Science, 22, 425-426. (in Chinese) [欧阳志云, 徐卫华 (2014) 整合我国自然保护区体系，依法建设国 家公园. 生物多样性, 22, 425-426.]

Peng YJ, Fan J, Xing SH, Cui GF (2018) Overview and classification outlook of natural protected areas in mainland China. Biodiversity Science, 26, 315-325. (in Chinese with English abstract) [彭杨靖, 㚞简, 邢韶华, 崔国发 (2018) 中国大陆自然保护地概况及分类体系构想. 生物多样性, 26, 315-325.]

Xiao WH, Hu L, Huang XQ, Xiao ZS (2019a) Using capture-recapture models in wildlife camera-trapping monitoring and the study case. Biodiversity Science, 27, 257-265. (in Chinese with English abstract) [肖文宏, 胡力, 黄小群, 肖治术 (2019a) 基于标记-重捕模型开展野生动 物红外相机种群监测的方法及案例. 生物多样性, 27 , 257-265.]

Xiao WH, Shu ZF, Chen LJ, Yao WT, Ma Y, Zhang YM, Xiao ZS (2019b) Using occupancy models in wildlife camera-trapping monitoring and the study case. Biodiversity Science, 27, 249-256. (in Chinese with English abstract) [肖 文宏，束祖飞，陈立军，姚武搯，马勇，张应明，肖治术 (2019b) 占域模型的原理及在野生动物红外相机研究中 的应用案例. 生物多样性, 27, 249-256.]

Xiao ZS, Chen LJ, Song XJ, Shu ZF, Xiao RG, Huang XQ (2019) Species inventory and assessment of large- and medium-size mammals and pheasants using camera trapping in the Chebaling National Nature Reserve, Guangdong Province. Biodiversity Science, 27, 237-242. (in Chinese with English abstract) [肖治术, 陈立军，宋相金，束祖飞， 肖荣高, 黄小群 (2019) 基于红外相机技术对广东车八 岭国家级自然保护区大中型兽类与雉类的编目清查与评 估. 生物多样性, 27, 237-242.]

Xiao ZS, Li XH, Wang XZ, Zhou QH, Quan RC, Shen XL, Li S (2014) Developing camera-trapping protocols for wildlife monitoring in Chinese forests. Biodiversity Science, 22, 704-711. (in Chinese with English abstract) [肖治术, 李欣 海, 王学志, 周岐海, 权锐昌, 申小莉, 李晟 (2014) 探 讨我国森林野生动物红外相机监测规范. 生物多样性, 22, 704-711.] 